\title{
Temporal changes in glycogenolytic enzyme mRNAs during myogenesis of primary porcine satellite cells
}

\author{
P.R. Henckel *, P.K. Theil, I.L. Sørensen, N. Oksbjerg \\ Department of Food Science, Danish Institute of Agricultural Sciences, Research Centre Foulum, P.O. Box 50, DK-8830 Tjele, Denmark
}

\begin{abstract}
The objective was to study the regulation of glycogenolytic enzyme mRNAs in porcine satellite cells during proliferation and differentiation. Beyond $80 \%$ confluence, cells were grown in absence or presence of $1 \mu \mathrm{M}$ insulin. The observed increases in abundance of mRNA for glycogenin, glycogen synthase, phosphorylase kinase, phosphorylase and glycogen debranching enzyme, and no alterations of the transporter molecule GLUT4, clearly indicate that glycogenolytic enzymes of potential importance to meat quality development are regulated at the gene level during myogenesis, and are heavily involved in muscle cell and muscle fibre development. The genes, however, are not influenced by insulin, and the lack of response to insulin of expression of gene-encoding enzymes involved in the formation and degradation of glycogen may question the applicability of porcine cell culture systems, like the one applied, as a model to study the regulation and regulatory mechanism of energy metabolism in muscles.
\end{abstract}

(c) 2006 Elsevier Ltd. All rights reserved.

Keywords: Cell culture; Gene expression; Glycogenolytic enzymes; Pig; Satellite cells

\section{Introduction}

To evaluate the quality of meat, whether from a consumer point of view or from the industry, three traits are considered of uppermost importance, namely drip loss, ultimate $\mathrm{pH}$ and colour. All of these traits are highly influenced by the rate and the extent of $\mathrm{pH}$ development postmortem (Bendall \& Swatland, 1989; Briskey, 1964). pH development is the result of the genetic prerequisites of the muscles for energy production and how these are affected by the environmental factors, to which animals can be exposed in connection with slaughter, such as handling procedures, transport conditions, lairage conditions, stunning method and killing procedure. To control all these factors is very difficult, even under experimental conditions. Nevertheless, the development and the application of whole animal models have given us a deeper insight into the importance of energy metabolism (Henckel, Karlsson, Jensen, Oksbjerg,

\footnotetext{
* Corresponding author. Tel.: +45 8999 1239; fax: +45 89991564.

E-mail address: poul.henckel@agrsci.dk (P.R. Henckel).
}

\& Petersen, 2002; Lindahl, Henckel, Karlsson, \& Andersen, 2006; Schäefer, Rosenvold, Purslow, Andersen, \& Henckel, 2002), but to study regulatory and adaptational mechanisms in energy conversion in muscle in response to individual stressors, more simple model systems like muscle cell cultures can be useful to provide knowledge that will enable us in the future to target more precise investigations in live animals with the aim of improving meat quality. The importance of insulin in maintaining glucose homeostasis and regulating carbohydrate metabolism is well recognised and described (Saltiel \& Kahn, 2001). Insulin in supraphysiological concentrations is in the present investigation used primarily as an enhancing agent to stimulate differentiation and fusion (Ørtenblad, Young, Oksbjerg, Nielsen, \& Lambert, 2003). As high levels of insulin are known to alter the sensitivity of myoblasts to insulin by reducing the rate of glucose uptake by the GLUT4 transporter and by reducing activation of the insulin signalling cascade (Huang et al., 2002), factors which also precede the development of noninsulin-dependent diabetes mellitus, we were interested in clarifying whether insulin at the concentrations used in 
the present experiment has any effects on energy metabolism of cultured cells during cell proliferation and differentiation. Insulin in supraphysiological concentrations has also been reported to cause a decrease in protein degradation as well as an increase in protein synthesis in myotubes derived from porcine myoblasts (Hembree, Hathaway, \& Dayton, 1991). Low concentrations of insulin have been shown to cause an increase in $\mathrm{Ca}^{2+}$-activated proteinase indicating an influence on the calpain system (Brooks, Goll, Peng, Greweling, \& Hennecke, 1983), which has recently been supported by the observations of Theil, Sørensen, Therkildsen, and Oksbjerg (2006a). Insulin also exerts an influence on myogenic factors (Theil, Sørensen, Nissen, \& Oksbjerg, 2006b).

The transition from satellite cell over proliferation and differentiation to fused myotubes is interesting in itself, and cell cultures offer ideal opportunities for studying regulatory mechanisms responsible for this development. However, most likely the transition also requires a complete change in energy metabolism. When satellite cells fuse into myotubes, the requirements for energy shift from a survival-/proliferative-related type to an activity-related type, which in addition to the necessary functions for survival requires huge amounts of energy for muscle contraction. We were thus interested in clarifying how this change in energy metabolism takes place by studying the transcription of a glucose transporter protein (GLUT4) and glycogenin and glycogen synthase, enzymes involved in synthesis of glycogen, and transcription of phosphorylase, phosphorylase kinase and glycogen debranching enzymes, which are involved in the degradation of glycogen. It was our intention to use muscle cell cultures as a model for studying energy metabolism in muscles of farm animals and considering the short lifespan of these cell cultures, we were interested in clarifying when one might expect changes to be caused by growth rather than development. Furthermore, any additional effects of administering exogenous insulin on transcription of glycogenolytic genes were evaluated. To fulfill these purposes, primary porcine satellite cells, isolated from $M$. semimembranosus, were cultured in vitro and harvested at various developmental stages.

\section{Materials and methods}

\subsection{Myotube cell cultures}

Cells were isolated from $M$. semimembranosus in three female pigs at 6 weeks of age, and a culture of satellite cells was established from each pig. The procedures for isolation and culturing of cells were described in detail by Theil et al. (2006b). Briefly, muscle tissue was excised, stripped of fat and connective tissue, finely chopped with a pair of scissors and digested in a $\mathrm{Ca}^{2+}$-free phosphate-buffered saline solution (PBS) containing glucose, collagenase II, trypsin and DNAse. Percoll gradients (20\% Percoll) were used to enrich the relative proportion of satellite cells in the cell suspension (Ørtenblad et al., 2003). Suspended cells isolated from
$2.0 \mathrm{~g}$ of tissue were equally distributed among wells in two 24 -well plates (or seeded at a density of $\approx 30,000$ viable cells per $\mathrm{cm}^{2}$ ). The two plates were seeded to study transcription levels in the absence and presence of insulin, respectively. When the cells had grown to near confluence (approximately $80 \%$ ), cell differentiation was induced by switching the medium to Dulbecco's modified Eagle's medium (DMEM) with 10\% foetal calf serum (FCS) for $24 \mathrm{~h}$, and then to DMEM containing 5\% FCS. From $80 \%$ confluence, the cells were grown either in the absence or presence of $1 \mu \mathrm{M}$ of porcine insulin, and cytosine arabinosid was added to inhibit DNA synthesis. The cells were harvested from four wells per animal at approximately 50\% and $80 \%$ confluence (50cf and $80 \mathrm{cf}$, respectively), and after 0 , 1,2 or 3 days of induction of differentiation $(\mathrm{d} 0, \mathrm{~d} 1, \mathrm{~d} 2$ and $\mathrm{d} 3$, respectively). Within a plate, all four wells in a column were harvested at the same stage.

\subsection{Real time $R T-P C R$}

Sample preparation, RNA extraction, cDNA synthesis and real time RT-PCR are described in detail by Theil et al. (2006a). In short, cells harvested during proliferation (50cf and $80 \mathrm{cf}$ ) were pooled from four wells, while cells harvested during differentiation were pooled from two wells, centrifuged at $1000 \mathrm{~g}$ for $10 \mathrm{~min}$ and stored at $-80^{\circ} \mathrm{C}$ until analysis. The RNA was extracted using the RNeasy mini kit (Qiagen, Albertslund, Denmark), and the total RNA was assessed after dilution by measuring the absorbance at $260 \mathrm{~nm}\left(\mathrm{~A}_{260}\right)$.

Purified RNA was reversely transcribed with oligo-dT primers and Superscript II RNase H reverse transcriptase kit (Invitrogen, Taastrup, Denmark). Reversely transcribed material $(1 \mu \mathrm{l})$ was amplified with TaqMan Universal PCR Master Mix and detected quantitatively by fluorescent MGB probes using the ABI 7900 HT detection system (Applied Biosystems, Stockholm, Sweden). Primers and probes were designed specifically for each gene by using Primer Express 2.0 software (Applied Biosystems, Stockholm, Sweden). Details of primer/probe design and runs of real time RT-PCR are given in Table 1. Amplicon length was tested after real time RT-PCR analysis on a $2 \%$ agarose gel, and the single 1 amplicon length agreed with the predicted length based on the nucleotide sequences (data not shown) analysed in duplicate using the ABI 7900HT detection system (Applied Biosystems, Stockholm, Sweden). Expression of target genes was normalised according to GAPDH and $\beta$-actin (housekeeping genes) (Theil, Labouriau, Sejrsen, Thomsen, \& Sørensen, 2005). The sequences of forward primers, MGB probes and reverse primers were as follows:

Glut 4: 5'-TGTGGGTGGCATGTTCTCT-3', 5'-GCAGGAAG-3', 5'-CAGCATTGCCTTCTTCCTTC-3'. Glycogenin: 5'-ATCAGCTGTTGCACCTTGCTT-3', 5'-TGAGCAAGGTAGTTTTGATGGTGG-3', 5'-GCTGCTAAAAAATGTGTTCAGTAAACC- $3^{\prime}$. 
Table 1

Accession numbers, amplicon location, amplicon length, range of $\mathrm{Ct}$ values in samples and slope of standard curve of the analysed genes

\begin{tabular}{|c|c|c|c|c|c|}
\hline Gene & Accession no. & $\begin{array}{l}\text { Amplicon location } \\
\text { (exon-exon) }\end{array}$ & $\begin{array}{l}\text { Amplicon length } \\
\text { (bp) }\end{array}$ & $\begin{array}{l}\text { Range of } \mathrm{Ct} \\
\text { in samples }\end{array}$ & $\begin{array}{l}\text { Slope of } \\
\text { std. curve }\end{array}$ \\
\hline GLUT 4 & AF 141956 & $2-3$ & 82 & $31-35$ & -3.1121 \\
\hline Glykogenin & Svinegenom & $4-5$ & 80 & $24-28$ & -3.4103 \\
\hline Glycogen synthase & AJ507152 & $13-14$ & 74 & $21-27$ & -3.1872 \\
\hline Glycogen phosphorylase & Svinegenom & $5-6$ & 79 & $24-32$ & -3.4853 \\
\hline Phosphorylase kinase & AF091609 & $3-4$ & 77 & $25-29$ & -3.2835 \\
\hline Glycogen debranching enzyme & AJ511338 & $34-35$ & 78 & $24-29$ & -3.3022 \\
\hline$\beta$-actin & AY550069 & $1-2$ & 86 & $19-22$ & -3.13 \\
\hline GAPDH & AF017079 & $2-3$ & 76 & $20-24$ & -3.40 \\
\hline
\end{tabular}

Glycogen synthase: 5'-CCGGCTTCGGCTGCTT-3', 5'CGCAGACCCCTCGGCTTACGGTATC-3', 5'-CCGCCGGTCCAGAATG-3'.

Glycogen debranching enzyme: 5'-TGTTCTTTCTCGACATTATGTTCATCT-3' ${ }^{\prime}$ ''-AGCGATCCCCTTGGAAAGGACTTCCA-3'， 5'-TGTCCATTCTCGTTGGTCAGTT-3'.

Phosphorylase kinase: 5'- CATCCTGCGCAAGGTCTCA-3', 5'-CACCCCAACATCATAACAGCTCAAGGACA-3', 5'-GGAAGAAGAAAGTGTTGGTCTCATAA- $3^{\prime}$

Glycogen phosphorylase: 5'- GTGGACACACAGGTGGTGTG-3', 5'-TGCCCTACGACACACCCGTGCC3', 5'-GCATGGTATTGACGACGTTGTT-3'.

\subsection{Calculations and statistics}

The RNA concentration was calculated as: RNA concentration $(\mu \mathrm{g} / \mathrm{ml})=40 \times \mathrm{A}_{260} \times$ dilution factor. The experiment was regarded as a split-plot design, and mRNA quantities were analysed using the MIXED procedure of SAS (SAS Inst., Inc., Cary, NC) as described by Littell, Milliken, Stroup, and Wolfinger (1996). Effects of developmental stage, insulin and stage $\times$ insulin interaction were tested, and repeated measurements made on cells originating from the same pig were accounted for by incorporating a random effect of pig nested within stage and insulin level. To evaluate mRNA quantities, data were obtained as $\mathrm{Ct}$ values (the cycle number at which logarithmic plots crosses a calculated threshold line) according to the manufacturer's guidelines, and were used to determine $\Delta \mathrm{Ct}$ values $(\Delta \mathrm{Ct}=$ $\mathrm{Ct}$ of the target gene - Ct of the housekeeping gene). When testing transcription of $\beta$-actin and GAPDH (house keeping genes), the RNA concentration $(\mu \mathrm{g} / \mathrm{ml})$ was incorporated as a covariate. To exclude potential bias because of averaging data that had been transformed through the equation $2^{-\Delta \Delta \mathrm{Ct}}$, all statistics were performed at the $\Delta \mathrm{Ct}$ stage. LSMEANS of $\Delta \mathrm{Ct}$ values of target genes were normalised to the level observed at $50 \%$ confluence by calculating the $\Delta \Delta \mathrm{Ct}$ values $(\Delta \mathrm{Ct}$ observed at a given stage $-\Delta \mathrm{Ct}$ observed at $50 \%$ confluence), and the relative mRNA quantity was calculated by using the formula: Relative quantity= $2^{-\Delta \Delta \mathrm{Ct}}$. However, the base number of 2 was changed accordingly, if the PCR efficiency was below $100 \%$.

\section{Results}

\subsection{Myoblast fusion and effect of insulin}

Myoblasts were grown in growth medium, then induced to differentiate by a change to fusion medium (10\% FCS) either in the presence or absence of insulin, as described in Section 2. At d1 the cells were confluent, and alignment of cells was initiated. The medium was changed at d1 to $5 \%$ FCS, and extensive fusion to multinucleated myotubes was visualised during the following $48 \mathrm{~h}$, whereas no changes were visualised after that point (i.e. from $\mathrm{d} 3$ to $\mathrm{d} 4$ ).

Transcription of GLUT4 transporter molecule (Fig. 1a) was neither effected by insulin nor by stage, and remained surprisingly constant throughout the period. Glycogenin transcription (Fig. 1b), on the other hand, displayed a steady and significant increase in expression until an apparent plateau was reached at $\mathrm{d} 3$ $(P<0.001)$. Insulin treatment had no effect on glycogenin expression $(P=0.76)$. Transcription of glycogen synthase (Fig. 1c), which encodes the enzyme responsible for the elongation of the glucose string, was also increased during proliferation and differentiation $(P<0.001)$, but levelled off a day earlier. As for the glycogenin gene no effect of insulin was observed $(P=0.47)$. A similar response was observed for the expression of the glycogen debranching enzyme (Fig. 1d). Phosphorylase kinase (Fig. 1e) activates glycogen phosphorylase, and is, as such, part of the regulatory system. The transcription peaked at day 2 with an almost 10 -fold increment and then decreased significantly throughout the "stable" period $(P<0.01)$. The expression of glycogen phosphorylase (Fig. 1f) displayed the most dramatic changes. At the third day after stimulation of differentiation, an almost 50-fold increase in expression had taken place, but there was no significant difference between the values observed at day 2, 3 and 4. As for the genes involved in the synthesis of glycogen, transcription of genes involved in degradation was not influenced by insulin.

\subsection{Evaluation of housekeeping genes}

Transcription of $\beta$-actin was slightly but significantly influenced by development $(P<0.022)$, but not by insulin, whereas GAPDH was affected both by insulin $(P<0.001)$ 

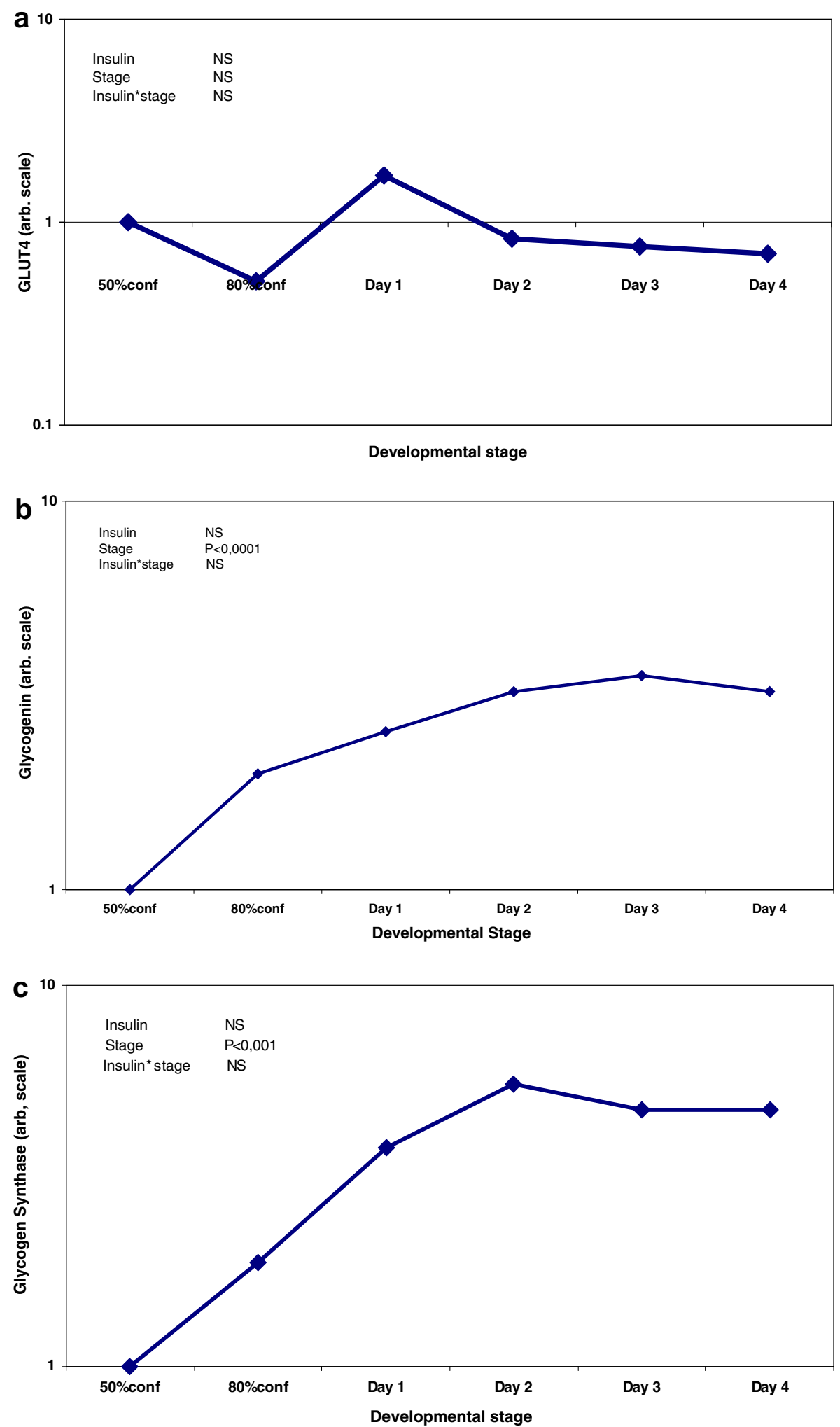

Fig. 1. (a)-(f) Changes during the development in the transcriptional level (expressed relative to the level observed at $50 \%$ confluence) of the substances using a $\log$ scale on the $y$-axis. Significant effects of insulin and developmental stage as well as their interactions are indicated in the individual figures.

and by development $(P<0.001)$ as well as displaying an interactive effect of insulin $*$ development $(P<0.04)$. However, no conclusions regarding effects of stage and insulin depended on the choice of housekeeping gene applied. Furthermore, the changes of transcription of housekeeping genes were much lower than the changes 

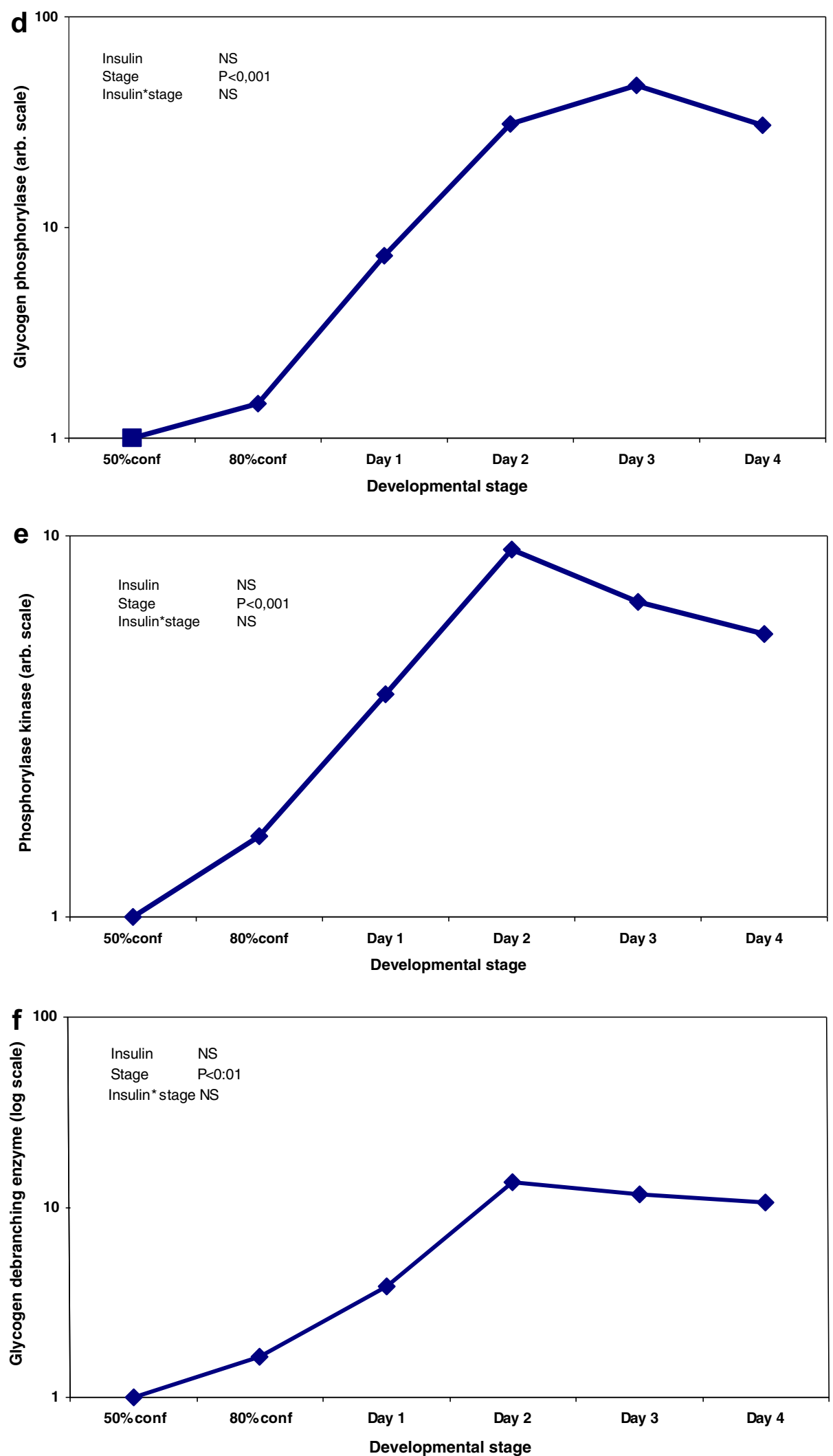

Fig. 1 (continued)

observed for the target genes. Hence to obtain a more robust normalisation, the mean $\mathrm{Ct}$ values of GAPDH and $\beta$-actin were calculated and employed to normalise transcription of target genes as was done for suckled and non-suckled mammary glands of lactating sows (Theil et al., 2005). 


\section{Discussion}

It is customary to view development of myoblast cell cultures as a two-stage process, which includes proliferation and differentiation. An alternative proposal for subdivision of these stages has been put forward by Steenstrup and Hannon (2000), who suggested that differentiation actually should be subdivided into two phases: exit from the cell cycle and expression of muscle-specific genes, and fusion into multinucleated fibres or myotubes. As we are dealing with developmental changes the three-stage model appears in our view to be more appropriate as it allows for a more detailed description that relates to all the important events in a cell transforming from one function to a totally different function. However, given the main purpose of this investigation, it may not be of any significant importance in this context. According to Florini (1989), the different stages of development can be identified by the level of activity of creatine kinase (CK), and also the level of myogenin has been suggested as an indicator of developmental stage (Florini, Ewton, \& Roof, 1991). CK values and transcriptional level of myogenin at the different stages, using the same cell cultures as used in the present study, are given by Theil et al. (2006b). Based on these results, which showed that both $\mathrm{CK}$ activity and myogenin expression peaked at day 2, although the shape of the curve differed, and on a visual examination of the cell cultures, one might suggest that the time from $50 \%$ to $80 \%$ confluence is exclusively proliferative. The time from $80 \%$ to day 1 is a time of exit from the cell cycle and of initiating expression of muscle-specific genes, and the time from day 1 to day 2 is a period of fusion, and thereon observed changes are primarily caused by growth of muscle fibres. By visual examination, however, one might expect the fusion to be terminated at day three, which points to a slight discrepancy in the evaluation of the stages between the methods. We can be certain, however, that changes observed from day 3 to day 4 can be attributed to growth or treatment only and not to development.

During normal conditions in vivo, insulin facilitates muscle glycogen synthesis through action on both glucose transport and glycogen synthase activity. The effect on glucose transport is mediated via insulin receptors. When insulin levels are increased, the subsequent activation of the intracellular signalling system via the receptors results ultimately in translocation of GLUT4 to the cell membrane. In normal, rested condition, GLUT4 is sequestered into specialised storage vesicles within the muscle fibres. By declining insulin levels, the reverse process is initiated by endocytosis of GLUT4 on the membrane surface (Watson $\&$ Pessin, 2001). A review of the signals participating in GLUT4 translocation is given by Patel, Huang, and Klip (2006). In vivo, chronic hyperinsulinemia has been shown to imply a reduction in insulin-mediated glycogen synthesis in muscles (Del Prato et al., 1994). Bertacca et al. (2005) showed using human myoblasts (no fusion) that this reduced glycogen synthesis by exposure to moderate hyper- insulinemia was not caused by alterations in GLUT4 at the protein level, but was rather attributed to alterations both in transcriptional and activity level of proteins involved in the insulin-signalling system. In L6 myotubes, a $24 \mathrm{~h}$ pretreatment with high insulin and high glucose level also implied a decrease in insulin-stimulated GLUT4 translocation together with a reduced activation of the insulin-signalling cascade and also a concomitant $40 \%$ increase in basal glucose uptake, which was considered to be an adaptive response to the treatment (Huang et al., 2002). The fact that we observed no influence on the transcriptional level of GLUT4 (Fig. 1a) agrees with these results. It should be noted that long-term exposure to insulin has also been shown to induce an increase in GLUT4 mRNA in human myotubes (Al-Khalili et al., 2005).

It is obvious that the type of cell culture used is of significant importance for the interpretation of the data, as to a certain extent it is a phenotypic response that is displayed by the cells. GLUT4 transporter content has been shown to vary considerably from muscle to muscle, and oxidative muscles display higher contents of GLUT4 than glycolytic muscles, and differences between bovine and porcine muscles have also been shown (Duhlmeier, Hacker, Widdel, von Engelhardt, \& Sallmann, 2005). In our case the initial cell culture was produced from the semimembranosus muscle, which is extremely glycolytic. Consequently, we may expect a low content of GLUT4 in these cell cultures, and this may partly explain the lack of response to insulin. When looking at development, the results clearly indicate that there is no change in the expression of GLUT4. The potential capacity for transmembrane glucose transport is thus unaltered during all three stages of myogenesis.

Glycogenin is the protein precurser of glycogen. It is characterised by autocatalytic activity enabling it to add several glucose units from UDP-glucose to its active Tyr194 site (Campbell \& Cohen, 1989; Smythe, Caudwell, Ferguson, \& Cohen, 1988), before it becomes an integrated part of glycogen synthase for further formation of glycogen, catalysed by glycogen synthase and glycogen branching enzyme. Glycogenin and glycogen synthase have been shown to exist in a 1:1 molar ratio (Pitcher, Smythe, Campbell, \& Cohen, 1987). As the amount of glycogenin will have an influence on the storage capacity of glycogen in muscles, it has been suggested that the production of the active glycogenin primer has at least the potential to be an overall ratelimiting process in the formation of glycogen, even more important than the phosphorylation and dephosphorylation processes involved in the regulation of glycogen synthase and phosphorylase (Alonzo, Lomako, Lomako, \& Whelan, 1995). More recent data, however, does not support this concept. Hansen, Derave, Jensen, and Richter (2000) showed that both the protein level and the activity of glycogenin were poorly correlated to maximal attainable glycogen content and suggested glycogen concentration as a possible candidate for regulation. This hypothesis has recently been supported by Jensen et al. (2006), who showed that high glycogen levels implied a reduction in glycogen 
synthase activity, but detailed information on how this activity is regulated and its importance to glycogen levels remains to be elucidated. We observed a two-fold increase in mRNA for glycogenin (Fig. 1b) during the proliferative stage and a further 1.5-fold increase until day 3. These results agree with those of Pak, Sangaralingham, and Pang (1999), who showed that high levels of glycogenin appeared to correlate to the proliferative state of cardiac myocyte growth and reduced levels of glycogenin correlated to the postmitotic period. The role of glycogenin if any in regulating the ratio of proglycogen to macroglycogen both during synthesis and degradation is still an open question.

The synthesis of glycogen is primarily controlled through regulation of glycogen synthase. The enzyme is allosterically regulated by glucose-6-phosphate and covalently by reversible phosphorylation at nine known sites (Wilson et al., 2005). The enzyme is inactivated by phosphorylation, and full activity can be restored by the presence of glucose6-phosphate. Insulin may stimulate glycogen synthase by several signalling transduction pathways, but it is currently believed to be mainly mediated via the phosphatidyl-inositol 3-kinase/protein kinase B pathway. This leads to inactivation of glycogen synthase kinase-3 (Gaster et al., 2004), which implies dephosphorylation and activation of glycogen synthase, as already shown by Cohen (1993). Also, the level of glycogen has been shown to exert a strong influence on the activity of glycogen synthase (Danforth, 1965; Halse, Bonavaud, Armstrong, McCormack, \& Yeaman, 2001; Jensen et al., 2006).

We observed a two-fold increase in mRNA for glycogen synthase (Fig. 1b) initially during proliferation and a further 2-fold increase during the time of exit from the cell cycle and initiation of expression of muscle-specific genes, peaking at day 2 after a further 1.5-fold increase during the period of fusion into multinucleated fibres or myotubes. This was followed by a stable or slight decrease in expression throughout the rest of the experimental period. Insulin had no effect on the transcriptional level of glycogen synthase nor on any of the other enzymes investigated, which supports the concept that the effect of insulin is primarily mediated via posttranscriptional control rather than regulated at the transcriptional level.

We did, however, observe a significant increase in the transcriptional level of GAPDH, implying a possible increase in activity of the glycolytic pathway for energy or ATP production as an effect of insulin. GAPDH has previously been used histochemically as an indicator of the glycolytic capacity of muscle fibres.

Complete degradation of glycogen involves two enzymes: glycogen phosphorylase and glycogen debranching enzyme. Glycogen phosphorylase catalyses the sequential phosphorylation and liberation of glucose from the outer chains of the glycogen molecule until it reaches the fourth glucose unit from the branching point (Walker \& Whelan, 1960). At this time the debranching enzyme takes over. This enzyme has a dual function; it first acts as a transferase and moves three glucose units from the side chain to the main chain, and then the remaining glucose units from the short chain are liberated as free glucose (Bates, Heaton, Taylor, Kernohan, \& Cohen, 1975) in contrast to the glucose liberated by glycogen phosphorylase which is phosphorylated (glucose-1-P). Glycogen phosphorylase exists in an active and an inactive form, and activity is initiated by phosphorylation of the enzyme by phosphorylase kinase. Apart from this main function phosphorylase kinase may also be part of the regulation of glycogen synthase as it has been shown to be the likely physiological kinase for ser-7, an active site at the N-terminal end of the enzyme.

We observed an almost 50-fold increase in transcriptional level for glycogen phosphorylase (Fig. 1f) from 50\% confluence to day 3, a 9.4-fold increase in phosphorylase kinase (Fig. 1e) from 50\% confluence to day 2 and a 13 -fold increase in mRNA for glycogen debranching enzyme (Fig. 1d) over the same time period. The development from satellite cell to fused myotubes thus implies a complete change in capacity for glycogen metabolism, a transition that favours the capacity for glycogen degradation, which is to be expected. The large increase in capacity for glycogen degradation enables the myotubes to produce large amounts of energy (ATP) locally by glycolysis. This is a characteristic of most muscles in pigs, but in particular the one from which the cell cultures were originally derived. The lack of effect of insulin on these parameters indicates that caution should be taken when comparing such results to live conditions. It would be worthwhile to investigate whether this apparent insulin insensitivity is due to the fact that we worked on cell cultures or it can be attributed to muscle type and hence is a more or less general feature of pig muscles.

Most effects of development indicate that fusion is terminated at day 2. However, both the results of transcriptional level of phosphorylase as well as visual examination of the cell cultures indicates that adaptational changes may still occur from day 2 to day 3 . We are consequently left with only 1 or 2 days in which we can perform investigation on the effect on energy metabolism of other stressors like hypoxia, electrical stimulation or exposure to gasses. The model used here thus offers opportunities to study the effects of short-term stressors and rapid recovery from such stressors, whereas other models should be chosen for studying the effects of longer-term stress and slow recovery. The apparent insensitivity to insulin, however, should be clarified, before valid comparisons to live conditions can be performed.

\section{References}

Al-Khalili, L., Forsgren, M., Kannisto, K., Zierath, J. R., Lönqvist, F., \& Krook, A. (2005). Enhanced insulin stimulated glycogen synthesis in response to insulin, metformin or roziglitazone is associated with increased mRNA expression of GLUT4 and peroxisomal proliferator activator receptor gamma co-activator 1. Diabetologica, 48, 1173-1179.

Alonzo, M. D., Lomako, J., Lomako, W. M., \& Whelan, W. J. (1995). A new look at the biogenesis of glycogen. Faseb Journal, 9, 1126-1137. 
Bates, E. J., Heaton, G. M., Taylor, C., Kernohan, J. C., \& Cohen, P. (1975). Debranching enzyme from rabbit skeletal muscle; evidence for the location of two active centres on a single polypeptide chain (1975). FEBS Letters, 58, 181-185.

Bendall, J. R., \& Swatland, H. J. (1989). A review of the relationships of $\mathrm{pH}$ with physical aspects of pork quality. Meat Science, 24(2), 85-126.

Bertacca, A., Ciccarone, A., Cechetti, P., Vianello, B., Lauranza, I., Maffei, M., et al. (2005). Continually high insulin levels impair Akt phosphorylation and glucose transport in human myoblast. Metabolism Clinical and Experimental, 54, 1687-1693.

Briskey, E. J. (1964). Etiological status and associated studies of pale, soft, exudative porcine musculature. Advances in Food Research, 13, 89-178.

Brooks, B. A., Goll, D. E., Peng, Y. S., Greweling, J. A., \& Hennecke, G. (1983). Effect of alloxan diabetes on a $\mathrm{Ca}^{2+}$-activated proteinase in rat skeletal muscle. American Journal of Physiology, 244(3), C175-C181.

Campbell, D. G., \& Cohen, P. (1989). The amino acid sequence of rabbit skeletal muscle glycogenin. European Journal of Biochemistry, 185, 119-125.

Cohen, P. (1993). Dissection of the protein-phosphorylation cascades involved in insulin and growth factor-action. Biochemical Society Transactions, 21(3), 555-567.

Danforth, W. H. (1965). Glycogen synthetase activity in skeletal muscle: interconversion of two forms and control of glycogen synthesis. Journal of Biological Chemistry, 240(2), 588-593.

Del Prato, S., Leonetty, F., Simonsen, D. C., Sheehan, P., Matsuda, M., \& DeFronzo, R. A. (1994). Effect of sustained physiological hyperinsulinemia and hyperglycemia on insulin secretion and insulin sensitivity in man. Diabetologia, 37(10), 1025-1035.

Duhlmeier, R., Hacker, A., Widdel, A., von Engelhardt, W., \& Sallmann, H.-P. (2005). Mechanisms of insulin-dependent glucose transport into porcine and bovine skeletal muscle. American Journal of Physiology Regulatory, Integrative and Comparative Physiology, 289, 187-197.

Florini, J. R. (1989). Assay of creatine kinase in microtiter plates using thio-NAD to allow monitoring at $405 \mathrm{~nm}$. Analytical Biochemistry, $182,399-404$.

Florini, J. R., Ewton, D. Z., \& Roof, S. L. (1991). Insulin like growth factor-I stimulates terminal myogenic differentiation by induction of myogenin gene-expression. Molecular Endocrinology, 5(5), 718-724.

Gaster, M., Brusgaard, K., Handberg, A., Højlund, K., Wojtaszewski, J. F. P., \& Beck-Nielsen, H. (2004). The primary defect in glycogen synthase activity is not based on increased glycogen synthase kinase- $3 \alpha$ I diabetic myotubes. Biochemical and Biophysical Research Communications, 319, 1235-1240.

Halse, R., Bonavaud, S. M., Armstrong, J. L., McCormack, J. G., \& Yeaman, S. J. (2001). Control of glycogen synthesis by glucose, glycogen, and insulin in cultured human muscle cells. Diabetes, 50, $720-726$.

Hansen, B. F., Derave, W., Jensen, P., \& Richter, E. A. (2000). No limiting role for glycogenin in determining maximal glycogen levels in rat skeletal muscles. American Journal of Physiology-Endocrinology and Metabolism, 278, E398-E404.

Hembree, J. R., Hathaway, M. R., \& Dayton, W. R. (1991). Isolation and culture of fetal porcine myogenic cells and the effect of insulin, IGF-I, and sera on protein turnover in porcine myotube cultures. Journal of Animal Science, 69(8), 3241-3250.

Henckel, P., Karlsson, A., Jensen, M. T., Oksbjerg, N., \& Petersen, J. S. (2002). Metabolic conditions in Porcine longissimus muscle immediately pre-slaughter and its influence on peri and post mortem energy metabolism. Meat Science, 62, 145-155.

Huang, C., Somwar, R., Patel, N., Niu, W., Török, D., \& Klip, A. (2002). Sustained exposure of L6 myotubes to high glucose and insulin decreases insulin-stimulated GLUT4 translocation but upregulates GLUT4 activity. Diabetes, 51, 2090-2098.

Jensen, J., Jebens, E., Brennesvik, E. O., Ruzzin, J., Soos, M. A., Engebretsen, E. M. L., et al. (2006). Muscle glycogen inharmoniously regulates glycogen synthase activity, glucose uptake, and proximal insulin signalling. American Journal of Physiology-Endocrinology and Metabolism, 290, E154-E162.

Lindahl, G., Henckel, P., Karlsson, A. H., \& Andersen, H. J. (2006). Significance of early post mortemtemperature and $\mathrm{pH}$ decline on colour characteristics of pork loin from different crossbreeds. Meat Science, 72, 613-623.

Littell, R. C., Milliken, G. A., Stroup, W. W., \& Wolfinger, R. D. (1996). $S A S(R)$ System for mixed models. Cary, NC: SAS Institute Inc., pp. $1-633$.

Ørtenblad, N., Young, J. F., Oksbjerg, N., Nielsen, J. H., \& Lambert, I. H. (2003). Reactive oxygen species are important mediators of taurine release from skeletal muscle cell. American Journal of Physiology-Cell Physiology, 284(6), C1362-C1376.

Pak, B. J., Sangaralingham, S. J., \& Pang, S. C. (1999). Molecular cloning and developmental expression of rat glycogenin in cardiac tissue. Molecular and Cellular Biochemistry, 194, 117-123.

Patel, N., Huang, C., \& Klip, A. (2006). Cellular location of insulintriggered signals and implications for glucose uptake. Pflügers Archives-European Journal of Physiology, 451, 499-510.

Pitcher, J., Smythe, C., Campbell, D. G., \& Cohen, P. (1987). Identification of the $38-\mathrm{kDa}$ subunit of rabbit skeletal muscle glycogen synthase as glycogenin. European Journal of Biochemistry, 169, 497-502.

Saltiel, A. R., \& Kahn, C. R. (2001). Insulin signalling and the regulation of glucose and lipid metabolism. Nature, 414, 799-806.

Schäefer, A., Rosenvold, K., Purslow, P., Andersen, H. J., \& Henckel, P. (2002). Physiological and structural events post mortem of importance for drip loss in pork. Meat Science, 61, 355-366.

Smythe, C., Caudwell, F. B., Ferguson, M., \& Cohen, P. (1988). Isolation and structural analysis of a peptide containing the novel tyrosylglucose linkage in glycogenin. EMBO Journal, 7, 2681-2686.

Steenstrup, T., \& Hannon, K. (2000). Isolation of a spontaneously fusing BC H1 muscle cell line: fusion alters the response to serum stimulation. In Vitro Cellular and Developmental Biology-Animal, 36(4), 241-248.

Theil, P. K., Labouriau, R., Sejrsen, K., Thomsen, B., \& Sørensen, M. T. (2005). Expression of genes involved in regulation of cell turnover during milk stasis and lactation rescue in sow mammary glands. Journal of Animal Science, 83, 2349-2356.

Theil, P. K., Sørensen, I. L., Nissen, P. M., \& Oksbjerg, N. (2006b). Temporal expression of growth factor genes of primary porcine satellite cells during myogenesis. Animal Science Journal, 77(3), 330-337.

Theil, P. K., Sørensen, I. L., Therkildsen, M., \& Oksbjerg, N. (2006a). Changes in proteolytic enzyme mRNAs relevant for meat quality during myogenesis of primary porcine satellite cells. Meat Science, 73, $335-343$.

Walker, G. J., \& Whelan, W. J. (1960). The mechanism of carbohydrate action 8. Structures of the muscle-phosphorylase limit dextrins of glycogen and amylopectin. Biochemical Journal, 76, 264-268.

Watson, R. T., \& Pessin, J. E. (2001). Intracellular organization of insulin signalling and Glut 4 Translocation. Recent Progress in Hormone Research, 56, 175-193.

Wilson, W. A., Skurat, A. V., Probst, B., de Paoli-Roach, A., Roach, P. J., \& Rutter, J. (2005). Control of mammalian glycogen synthase by PASkinase. Proceedings of the National Academy of Sciences of the United States of America, 102(46), 16596-16601. 